\title{
Computer Identification of Yeasts of the Genus Saccharomyces
}

\author{
By I. CAMPBELL \\ Department of Brewing and Biological Sciences, Heriot-Watt University, \\ Edinburgh $E H$ г I $H X$
}

(Received 28 December 1972)

SUMMARY

\begin{abstract}
A punched-card system of identification by computer is described, whereby matching at over $85 \%$ with the description of a recognized Saccharomyces species constitutes identification. The system is based on a set of 39 invariable descriptions of species, so defined that no species is related at higher than $85 \%$ matching coefficient to any other species.
\end{abstract}

\section{INTRODUCTION}

Computerized identification of bacteria has been described by various authors; the most useful systems appear to be those by Gyllenberg (1965) and Lapage, Bascomb, Willcox \& Curtis (1970). Steel (I962) reviewed various punched-card systems of identification, some of which required computer assistance. The use of punched cards for identification requires a set of standard cards to compare with the unknowns. Numerical analysis provides suitable groups of the genus Saccharomyces, which can represent standard species for identification of strains.

Previous analysis of the standard descriptions by van der Walt (1970 $a, b)$ of Kluyveromyces and Saccharomyces species (Campbell, 1972) indicated such extensive overlap of groups that two genera were not justified. Of the 59 species of the two genera, 25 were eliminated by $90 \%$ or higher matching (i.e. synonymy) with previously defined species. Unfortunately, Saccharomyces bayanus, S. cerevisiae, S. heterogenicus, S. inusitatus and S. urarum could not be distinguished by the form of standard description given by van der Walt (1970 $b$ ) but formed a single large cluster. Kocková-Kratochvílová, Pokorná \& Šandula ( 1966) and Kocková-Kratochvílová et al. (1968, 1969, 1970) extensively analysed that group of species, indicating that they formed clusters corresponding to formerly recognized species (Lodder \& Kreger-van Rij, I952) $S$. cerevisiae, $S$. cerevisiae var. ellipsoideus, $S$. carlsbergensis, $S$. heterogenicus, $S$. $\operatorname{logos}, S$. bayanus, $S$. steineri, $S$. italicus and $S$. willianus. It occurred to us that these small, easily defined groups would be more conveniently handled in analyses, and particularly in computerized identification, than would the large and widely variable species into which they were merged by van der Walt (1970b). The present paper offers a solution to the difficulty of classifying $S$. bayanus, $S$. cerevisiae and $S$. uvarum and simultaneously shows the advantages of a simple punched-card system of identification of yeasts.

\section{METHODS}

Yeast cultures. The strains of Saccharomyces for analysis were obtained from the National Collection of Yeast Cultures, Nutfield, England (NCYC), Centraalbureau voor Schimmelcultures, Delft, The Netherlands (CBS) and this Department (HWU). Unless another authority is quoted, nomenclature of species is according to van der Walt (1970a, $b$ ).

Characters for numerical analysis. A preliminary determination of matching coefficient, 
$S_{s}$ (Sneath, 1972), between strains was determined by using the 54 characters described by Campbell (1972) for analysis of strains of other Saccharomyces species. $S_{s}$ was determined from both positive and negative matches as described previously (Campbell, 1970).

For computer identification, a modified list of characters was used, employing mainly the properties listed in van der Walt's (I970 $a, b$ ) standard descriptions of species. Morphological and physiological properties were scored as described previously (Campbell, 1970). Omissions from van der Walt's list of assimilation tests were in accordance with Barnett's (I968) warning on the use of related biochemical tests for classification; also due to Barnett (I97I) was the reduction of van der Walt's I 3 fermentation tests to 5. Although Buhagiar \& Barnett (I 97I) used glucose, galactose, sucrose, melibiose and trehalose in their analysis of yeasts of strawberries, tests on glucose, galactose, sucrose, maltose and raffinose were found to be more convenient for the genus Saccharomyces. The range of characters also included serological properties A, B, C, D, E and F (Campbell, I97I), growth in $8 \%$ and $12 \%(\mathrm{v} / \mathrm{v}$ ) ethanol media and under anaerobic conditions, and clearing of chalk and tributyrin agars (Campbell, I970). The complete range of tests is indicated by the column headings of Table I.

Numerical analyses. Two computer programs were used on the IBM $4 \mathrm{I} 30$ computer of the Heriot-Watt University. Program I was that described previously for comparison of groups of 24 strains (Campbell, 1970) and provided (a) matching coefficients of each strain with all others, $(b)$ matched pairs of strains at 95 to $100 \%$ matching, 90 to $95 \%$, etc., at $5 \%$ intervals, and $(c)$ a triangular matrix of strains with matches indicated at $5 \%$ intervals. From these data a dendrogram of the 24 strains was prepared without further computer assistance, by arranging strains in clusters at the highest similarity level expressed to the nearest $5 \%$. Since the number of comparisons was constant, the running time of a single 24-strain analysis was constant $-58 \mathrm{~s}$.

Program 2 was used for more general comparisons, by which groups of up to 96 strains were compared, and arranged in matched pairs at $5 \%$ intervals. Program 2 was modified from part $(b)$ of program I, and compared strains from $100 \%$ down to only $75 \%$ matching. Since any number of strains up to 96 could be examined, and the number of matches $>75 \%$ varied according to the properties of strains, the running time varied, but was usually approx. 3 min with 96 strains.

Identification of unknown cultures. Each species of Saccharomyces was defined by an invariable description of 58 characters (Table $\mathrm{I}$ ). Properties of a newly isolated strain were punched on the 80-column card in the correct order, and the cards were tested against the deck of 39 Saccharomyces cards by program 2, above. The highest matching coefficient $>85 \%$ with a known species was accepted as identification, but the best match in the 80 to $85 \%$ range would be considered as provisional identification where no better match was obtained.

\section{RESULTS}

Previous numerical analyses (Kocková-Kratochvílová et al. I966, 1968, 1969, 1970; Campbell, I970) showed that the yeasts now classified as Saccharomyces bayanus, S. cerevisiae and $S$. uvarum (by van der Walt, $1970 \mathrm{~b}$ ) formed taxonomic groups approximating to the species described by Lodder \& Kreger-van Rij (I952). A larger collection of strains than before (Campbell, I970) was analysed to determine the range of properties which defined each group. The resulting dendrogram was so similar to patterns already published (KockováKratochvílová et al. I 969, I970; Campbell, 1970) that only a small part is reproduced here, as Fig. I, for discussion later in this paper. Many of the strains from which the complete dendrogram was prepared have already been described (Campbell, I970, 1972) and a list 


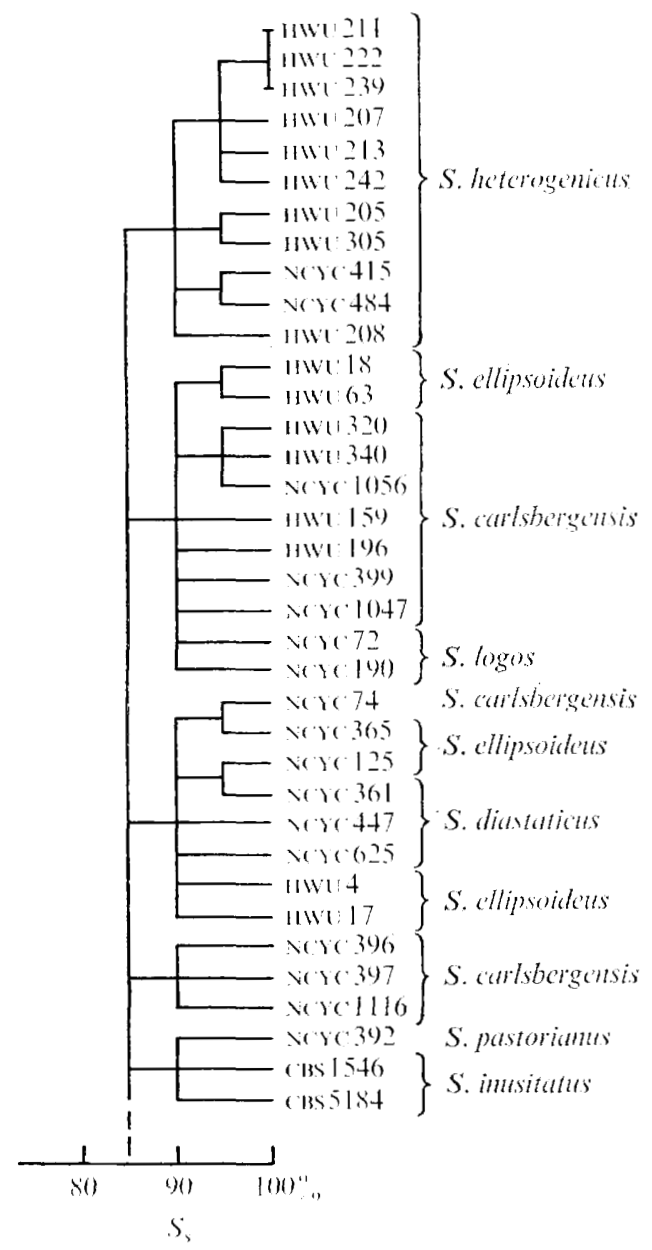

Fig. 1. Taxonomic dendrogram of a selection of Saccharomyces species.

of properties is not repeated here in full, but Table $\mathrm{I}$ is effectively a summary of these properties. Spores, if formed, were not considered (Barnett, I960, 197I ; Campbell, 1972), and Kocková-Kratochvílová et al. (1966, I968, I969, 1970) determined only the number of spores/ascus in their analyses.

Fourteen clusters were separated at a matching level of 80 to $85 \%$, leaving a group of miscellaneous strains, mainly Saccharomyces chevalieri and S. ellipsoideus Hansen. Not all strains allocated to the same cluster were of identical fermentation properties, e.g. the melibiose-fermenting strains NCYC 72 and 190 (formerly $S$. logos) and strains of the former species $S$. carlsbergensis (Lodder \& Kreger-van Rij, 1952) were in the same group as HWU I 8 and 63, melibiose-negative strains classified as $S$. ellipsoideus Hansen. Fermentation of melibiose, of fundamental importance to van der Walt's classification ( I970 b), was one of the few differences between strains in that cluster, which was nevertheless listed as $S$. carlsbergensis since seven of the eleven strains were of that species. A second group, also identified as $S$. carlsbergensis, was formed of three strains. The other eleven groups were identified as S. bayanus, S. cerevisiae, S. ellipsoideus Hansen, S. heterogenicus, S. inusitatus, S. italicus, 


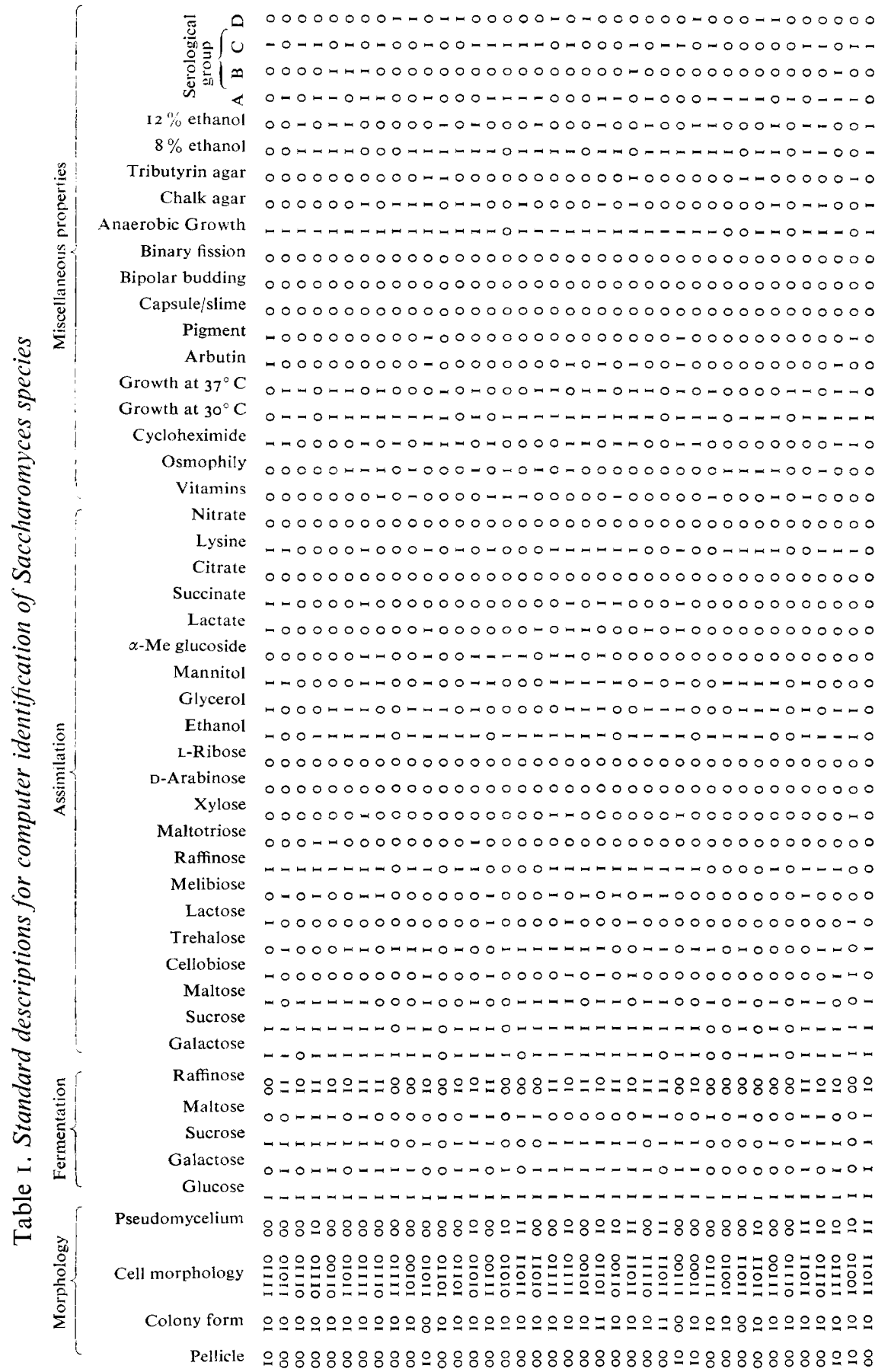


S. oriformis Osterwalder, S. steineri Lodder \& K reger-van Rij, S. urarum, S. veronae Lodder \& Kreger-van Rij and $S$. willianus Saccardo. Strains of S. diastaticus, claimed to be synonymous with $S$. cererisiae (Campbell, 1972), were included in a group composed mainly of maltotriose-fermenting strains classified as $S$. ellipsoideus.

Descriptions of species based on the properties of strains in each cluster in Fig. 1 are presented in Table I; where strains showed different reactions in tests, the result given by the majority of strains was accepted. Each line of Table I represents the information on one card. Data for the cards of other Saccharomyces species were provided by modified (Campbell, 1972) standard descriptions (van der Walt, 1970 $a, b$ ) and by our own results, including the additional tests described in Methods. Variation in properties was not considered; the cards recorded a fixed description of the species. The first four columns recorded the name of the species (e.g. SCER for Saccharomyces cerevisiae; SCAI and SCA2 for the two types of $S$. carlsbergensis). Positive reactions listed in Table I were allocated to the appropriate columns 5 to 62 . Where no strain of a species was available in our collection, van der Walt's description, supplemented by serological results (Campbell, I972), was used.

Saccharomyces rouxii, the description of which included many variable properties, was troublesome to define. Three cards were required, each differing from the other two by $15 \%$ (i.e. $S_{s}=85 \%$ ) of the properties. Saccharomyces rouxii I was closely matched $\left(S_{s} 90\right.$ to $95^{\circ}$ ) with NCYC strains I7I, 385 and 697 , received as S. bailii and S. bisporus. S. rouxii 2 was related at $S_{s} 85$ to $100 \%$ to NCYC strains I70, 38I, 567 and 568 , received as The third group was based on NCYC strains $4 I 7$ and 563 , received as $S$. acidifaciens (Nickerson) Lodder \& Kreger-van Rij, now synonymous with $S$. bailii (van der Walt, $1970 b$ ) by Campbell. Three fixed descriptions adequately covered the range of variation of $S$. rouxii as described (1972).

Kluyreromyces lactis, also defined by van der Walt (I970a) with extensive variation in properties, was easily defined in the form of an invariable punched-card description. When the closely related $\left(S_{s}>80 \%\right.$ ) species $K$. aestuarii, $K$. dobzhanskii, $K$. marxianus, $K$. phaseolosportus, $K$. vanudenii and $K$. wickerhamii had been defined, there was insufficient possibility of variation in $K$. lactis to allow two descriptions differing by $\Varangle 15 \%$ of properties. A single card, with properties based on NCYC strains 4I6, 570 and 57 I, sufficed for K. lactis. This meant that borderline strains between $K$. lactis and another closely related Kluyveromyces species were allocated in practice to the other species. All species of Kluyveromyces were described in Table I as Saccharomyces species (according to Campbell, 1972).

The resulting deck of cards was processed to ensure that after omission of certain properties from the earlier analysis, e.g. assimilation of glycine, histidine, methionine and tryptophan, and specific requirement for individual growth factors, the matching coefficient between all pairs of strains remained $<85 \%$. On the first test, this was not achieved in all comparisons. The descriptions were adjusted as necessary, but within the limits of variation of standard descriptions (van der Walt, $1970 a, b$ ), to reduce the matching coefficient between species to this level. When two species related at 80 to $85 \%$ were both related to a third at $S_{s} \geqslant 90 \%$, that mutually related species was deleted to leave the required space between species. In this way the temporarily restored species Saccharomyces oviformis Osterwalder and S. steineri Lodder \& Kreger-van Rij were removed again from the list. In other cases, properties in the description of species were altered to produce the necessary difference between species. The two types of $S$. carlsbergensis and $S$. ellipsoideus were insufficiently different to justify two cards per species, and the average results of each species were used. By such trial-and-error methods a set of descriptions of Saccharomyces species was produced in which no species was related at $S_{s} \geqslant 85 \%$ to any other species (Table I). 


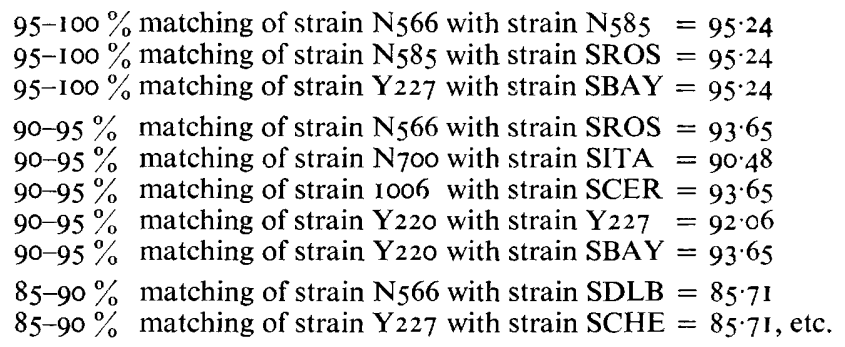

Fig. 2. Sample print-out of identification test of various Saccharomyces strains. (I) Only two lines of the $85-90 \%$ section are shown. (2) Identification of species: N566 and $\mathrm{N}_{5} 85=$ Saccharomyces rosei, $\mathrm{N} 700=S$. italicus, $\mathrm{Y}_{220}$ and $\mathrm{Y}_{227}=$ S. bayanus, $\mathrm{I} 066=$ S. cerevisiae.

The system was tested with a selection of strains recently isolated in this Department. All of 28 strains identified as Saccharomyces (i.e. including Kluyveromyces) by serological reactions were identified at $S_{s}>85 \%$ with known species; 17 were identified at $>90 \%$. The identifications were subsequently checked by comparing van der Walt's (1970a, $b$ ) descriptions with the results, and in all cases the computer's identification was acceptable. The form of computer identification is shown in Fig. 2 with, as examples, a selection of the strains which had been used in preparation of the cards. Note that strains appeared more than once in the print-out, but the highest matching coefficient was accepted as identification, e.g. strain 566 was Saccharomyces rosei and not $S$. delbrueckii. Also, all matches in each section were recorded, as the programme did not distinguish between strain numbers and codes for species.

\section{DISCUSSION}

The results confirm the claim (Campbell, I972) that the classification of three species, Saccharomyces bayanus, $S$. cerevisiae and $S$. uvarum, does not fairly represent the range of distinct subgroups of strongly fermentative yeasts. Kocková-Kratochvílová et al. (1966, 1968) noted that closely related strains were not necessarily of identical sugar fermentation patterns, and in our results a similar variation was noted in clusters at $>85 \%$ matching coefficient. Similar clusters were obtained by different sets of tests (Fig. I; KockováKratochvílová et al. 1968, 1969, I970; Campbell, I970, 1972). These groups corresponded to previously recognized species (Lodder \& Kreger-van Rij, 1952), but except for the subdivisions of the $S$. bayanus-cerevisiae-uvarum group, and restoring the species $S$. pastorianus Hansen, the modified (Campbell, I 972) nomenclature of van der Walt (I970a,b) was retained. Fig. I shows that $S$. inusitatus and $S$. pastorianus were indistinguishable, therefore in accordance with Gilliland's (I969) recommendation the epithet 'pastorianus' has been restored. Since computerized identification of $S$. cerevisiae and $S$. uvarum in their present form is impossible, these species have been subdivided as $S$. carlsbergensis Hansen, S. cerevisiae, $S$. ellipsoideus Hansen, S. uvarum and $S$. willianus Saccardo. Closely related, but distinct, species are $S$. bayanus, $S$. heterogenicus, $S$. italicus, $S$. pastorianus Hansen and S. veronae Lodder \& Kreger-van Rij. S. oviformis Osterwalder, intermediate between $S$. bayanus and $S$. heterogenicus, and S. steineri, between S. heterogenicus and S. italicus, were not required for identification.

The punched-card system described above is simpler than the systems described by earlier workers (Gyllenberg, 1965; Lapage et al. 1970). However, similar systems have been used successfully (see Steel, I962) in bacteriology, and the results with Saccharomyces strains suggest that they are equally applicable to yeasts. The choice of characters for analysis was 
dictated partly by the form of the standard descriptions of species (van der Walt, 1970 $a, b$ ) and partly by the variability of characters previously used but now omitted, as their variability may have distorted differences between species (Sneath \& Johnson, 1972). Also, the data on assimilation of nitrogen compounds, although available for a restricted range of species (Wickerham, 1946; Brady, 1965; Larue \& Spencer, 1968; Campbell, 1970), indicate such variation between strains that use for identification of species is inadvisable. The range of possible information for identification is thereby seriously reduced. Assimilation of nitrate was included in the tests, although always negative in Saccharomyces, as the cards were intended for later use with a wider range of yeasts (Campbell, 1973).

Identification by punched cards avoids the over-emphasis on fermentation tests, especially glucose, galactose, sucrose, maltose, melibiose and raffinose, which characterizes van der Walt's system of identification and classification of Saccharomyces. If species are to be classified by fermentation reactions, as is virtually the case at present (van der Walt, 1970 a, $b$ ), there is no need for the remaining morphological and assimilation tests. Alternatively, if all tests are regarded as important, some difference in fermentation properties within a species is unavoidable. In the present punched-card system, similar strains of different fermentation properties are placed in the same species. Strains HWU 208 and 242 ferment glucose and maltose only, but the other strains of the Saccharomyces heterogenicus cluster (Fig. I) ferment glucose, sucrose and maltose. Such variation is in agreement with the description of the species (van der Walt, 1970 ). Similarly, strains HWU I 8 and 63, unable to ferment melibiose and therefore previously classified as $S$. ellipsoideus Hansen, were placed in the same cluster as melibiose-fermenting strains of $S$. carlsbergensis Hansen on account of similar patterns of assimilation of sugars and organic acids. Strains of $S$. diastaticus were regarded as synonymous with $S$. ellipsoideus Hansen. Since fermentation of starch was therefore of no taxonomic value, maltotriose (Gilliland, 1956) was used in its place. Starch- and dextrin-fermenting strains are a serious nuisance in breweries (Andrews $\&$ Gilliland, 1952) but are insufficiently different from $S$. ellipsoideus to justify a separate species. On occasions, the computer matched an unknown culture equally with two species of the same serological properties, e.g. S. ellipsoideus and S. heterogenicus, both of serological group C (Campbell, 1970). The isolate was then identified as the species of the same fermentation reactions. Otherwise, strains were not necessarily identified as a species of van der Walt's $(1970 a, b)$ list with the same fermentation reactions.

Each unknown strain was tested against all species of Saccharomyces to find the highest matching coefficient. We did not examine the system of Lapage et al. (1970) whereby each description of species was tested against each unknown culture for the greatest likelihood of identity. The simpler system described above appeared to identify cultures satisfactorily, and made use of our existing programme for numerical taxonomy. A possible defect of the system arises from the use of matching coefficient based on positive and negative matches, rather than similarity coefficients (Sneath, 1972) based on positive matches only. Saccharomyces dairensis, $S$. delbrueckii, $S$. rouxii and $S$. telluris, with many negative properties, may have been shown more closely related than was justified (Beers, Fisher, Megraw \& Lockhart, I962).

Another disadvantage of a punched-card system, or indeed any computer system, is the requirement of a full set of tests. Since the tests chosen for computer testing are all read after 3 days, this is slow. In practice, we prefer to identify Saccharomyces species by serological reactions and morphology (Campbell, 1970, 1972). The exercise in computer taxonomy and identification confirmed the subdivision of Saccharomyces cerevisiae and $S$. uvarum into less-variable components, which are justified on serological evidence (Camp- 
bell, 1970). In addition, a satisfactory test of punched-card identification of yeasts of the genus Saccharomyces indicates interesting possibilities for similar identification of other genera less amenable to serological identification.

\section{REFERENCES}

ANDREWS, J. \& Gilliland, R. B. (I952). Super-attenuation of beer. A study of three organisms capable of causing abnormal fermentations. Journal of the Institute of Brewing 58, 189-196.

BarnetT, J. A. (1960). Comparative studies on yeasts. Nature, London 186, 449-45I.

BARnETT, J. A. (I968). Biochemical differentiation of taxa with special reference to the yeasts. In The Fungi, An Advanced Treatise, vol. III, The Fungal Population, pp. 557-595. Edited by G. C. Ainsworth and A. S. Sussman. London and New York: Academic Press.

BARNeTt, J. A. (197I). Selection of tests for identifying yeasts. Nature, London 232, $221-223$.

Beers, R. J., Fisher, J., Megraw, S. \& Lockhart, W. R. (1962). A comparison of methods of computer taxonomy. Journal of General Microbiology 28, 64I-652.

Brady, B. L. (1965). Utilization of amino compounds by yeasts of the genus Saccharomyces. Antonie van Leeuwenhoek 31, 95-102.

Buhagiar, R. W. M. \& Barnett, J. A. (1971). The yeasts of strawberries. Journal of Applied Bacteriology 34, 727-739.

CAMPBELL, I. (1970). Comparison of serological and physiological classification of the genus Saccharomyces. Journal of General Microbiology 63, I89-198.

CAMPBell, I. (1971). Numerical taxonomy of various genera of yeasts. Journal of General Microbiology 67, 223-231.

CAMPBELl, J. (1972). Numerical analysis of the genera Saccharomyces and Kluyyeromyces. Journal of General Microbiology 73, 279-30I.

Camprell, I. (1973). Numerical analysis and computer identification of Hansenula, Pichia and related yeast genera. Journal of General Microbiology (in the press).

Gilliland, R. B. (1956). Maltotriose fermentation in species differentiation of Saccharomyces. Comptes rendus des travaux du Laboratoire Carlsberg 26, $139-148$.

GyllenBerG, H. G. (1965). A model for computer identification of micro-organisms. Journal of General Microbiology 39, 40I-405.

Kocková-Kratochvílová, A., Pokorná, M. \& Šandula, J. (1966). The genus Saccharomyces (Meyen) Reess. I. A group of fermentation type II species completely fermenting raffinose. Folia microbiologica II, 188-199.

Kocková-Kratochvílová, A., Šandula, J., Sedlárová, L., Vojtková-Lepšíková, A. \& Kasmanová, M. ( 1969). Taxometric Study of the Genus Saccharomyces (Meyen) Reess, part I. Bratislava: Slovak Academy of Sciences.

Kocková-Kratochvílová, A., Sedlarová, L., Vojtková-Lepšíková, A. \& Šandula, J. (I970). Taxometric Study of the Genus Saccharomyces (Meyen) Reess. Saccharomyces cerevisiae Hansen and Related Species, part II. Bratislava: Slovak Academy of Sciences.

Kocková-Kratochvílová, A., Vojtková-Lepšíkova, A., Šandula, J. \& Pokorna, M. (1968). The genus Saccharomyces (Meyen) Reess. V. Saccharomyces willianus Saccardo, Saccharomyces bayanus Saccardo, Saccharomyces pastorianus Hansen, Saccharomyces heterogenicus Osterwalder, Saccharomyces steineri Lodder \& Kreger-van Rij. Folia microbiologica 13, 300-309.

Lapage, S. P., Bascomb, S., Willcox, W. R. \& CuRTIS, M. A. (1970). Computer identification of bacteria. In Automation, Mechanization and Data Handling in Microbiology, pp. 1-22. Edited by A. Baillie and R. J. Gilbert. London and New York: Academic Press.

LARUE, T. A. \& SPENCER, J. F. T. (1968). Utilization of purines and pyrimidines by yeasts. Canadian Journal of Microbiology 14, 79-86.

LODDER, J. \& Kreger-VAn Ru, N. J. W. (1952). The Yeasts, a Taxonomic Study. Amsterdam: North Holland Publishing Co.

SNeAtH, P. H. A. (1972). Computer taxonomy. In Methods in Microbiology, vol. 7A, pp. 29-98. Edited by J. R. Norris and D. W. Ribbons. London and New York: Academic Press.

SNeATH, P. H. A. \& Johnson, R. (I972). The influence on numerical taxonomic similarities of errors in microbiological tests. Journal of General Microbiology 72, 377-392. 
STEEL, K. J. (1962). The practice of bacterial identification. Symposia of the Society for General Microbiology I2, 405-432.

van deR WALT, J. P. (1970a). Genus 8. Kluyveromyces van der Walt emend. van der Walt. In The Yeasts, a Taxonomic Study, 2nd ed., pp. 316-378. Edited by J. Lodder. Amsterdam and London: North Holland. VAN DER WALT, J. P. (1970b). Genus 16. Saccharomyces Meyen emend. Reess. In The Yeasts, a Taxonomic Study, 2nd edn., pp. 555-71 8. Edited by J. Lodder. Amsterdam and London: North Holland Publishing Co.

Wickerham, L. J. ( I 946). A critical evaluation of the nitrogen assimilation tests commonly used in classification of yeasts. Journal of Bacteriology 52, 293-301. 